\title{
Urdimento
}

\section{COPEAU E A MÁSCARA}

\author{
José Ronaldo Faleiro ${ }^{I}$
}

\section{Resumo}

Este texto se propõe a apresentar alguns princípios e práticas desenvolvidos na Escola do Vieux-Colombier, de 1920 a 1924, em Paris, sob a condução pedagógica de Suzanne Bing e Jacques Copeau. Experiências aí realizadas, com o corpo em silêncio e com o rosto encoberto pela máscara, têm tido seguidores ao longo do século XX até os dias de hoje.

Palavras-chave: máscara, pedagogia teatral, formação do ator.

\begin{abstract}
This paper aims to present some principles and practices originated from the Vieux-Colombier School (1920 - 1924), in Paris, under the direction of Suzanne Bing and Jacques Copeau. Pedagogical activities realised then, with the body in silence and with masks, are nowadays a reference in the theatre.
\end{abstract}

Keywords: mask, pedagogy of theatre, actor's preparation.

All'alta fantasia qui mancò possa; Ma già volgeva il mil disio e 'l velle (...) Dante, Divina Commedia, canto XXXIII, vv. 142-3 do Paraíso.

Leitor infatigável, Copeau certamente não desconhecia a posição milenar da Igreja em relação à máscara. Enquanto numa cultura como a japonesa, por exemplo, ela constituía um elemento imprescindível, no Ocidente cristão é vista como condenável, já que, com ela, os seres humanos pretenderiam não só transformar-se, mas também, de certo modo, «apagar a figura que Deus lhes deu» (BORROMEU, in MARINIS, 2000, p. 160). Tal concepção persiste dos primórdios do Cristianismo até, praticamente, o século XIX. Na segunda metade do século XVIII, as objeções à máscara por parte de Carlo Goldoni e Jean-Georges Noverre (para citar apenas os dois) residem no fato de que ela oculta o rosto, anula a sua individualidade e expressão. De fato, atraído pela sentimentalidade da época dos «Coceurs Sensibles» [Corações Sensíveis], que criará a Comédie larmoyante [Comédia Lacrimosa], Goldoni afirma que "a máscara causa muito dano à ação do ator: seja na alegria, seja
IProfessor no Departamento de Artes Cênicas e no Programa de PósGraduação (Mestrado e Doutorado) do Centro de Artes/ Universidade do Estado de Santa Catarina (UDESC). Doutor em Artes do Espetáculo pela Universidade de Paris X-Nanterre, França. 


\section{Urdimento}

2"A conquista da 'máscara' foi, para todos e para Marcello, um caminho progressivo que esbarrou num número impreciso de fatos: da falta de uma tradição viva, e, portanto de um hábito mental e físico, à falta de técnica verdadeira, de 'instrumentos' idôneos" (STREHLER, 1974, p. 170). V. também as considerações de Dario Fo sobre o fato, no Manual Mínimo do Ator (1998, p. 46-47) e MARINIS, 2000, p. 162-163). na dor (...), é sempre o mesmo couro que se mostra, e por mais que gesticule e mude de tom, não comunicará jamais, pelos traços do rosto, que são os intérpretes do coração, as diversas paixões com as quais a sua alma se agita” (in CHANCEREL, 1941, p. 4), e Noverre, combatendo violentamente a máscara imposta até então aos bailarinos, pergunta, na carta IX das suas Lettres sur la danse [Cartas sobre a Dança], "por que a eclipsar [a fisionomia] no Teatro com uma máscara, e preferir a Arte grosseira à bela natureza? (...) Poderão as paixões trespassar o véu que o artista interpõe entre o espectador e ele?” (idem, ibidem, p. 6). Tal perspectiva ainda está presente na metade do século XX europeu (a estréia de Arlequim, Servidor de Dois Amos, pelo Piccolo Teatro de Milão, ocorre em 1947), a ponto de o ator Marcello Moretti considerar que a máscara exercia "uma espécie de tirania” sobre ele (STREHLER, 1974, p. 168)². Na França, o Journal de bord des Copiaus [Diário de Bordo dos Copiaus] (GONTARD, 1974, p. 137 e 138) registra a aceitação e a reticência do público relativamente a espetáculos com máscaras realizados em maio de 1928 na Borgonha; e em 1932, HUSSENOT confirma que os franceses não gostam da máscara, "a pretexto de tratar-se de algo morto, rígido, inexpressivo, que não conseguiria substituir o rosto humano (...)” (1932, p. 8).

Foi, portanto, dentro desse contexto de desconfiança em relação à máscara que Jacques Copeau utilizou esse objeto, muitas vezes tido por "um rosto falso atrás do qual esconder os traços da face com o objetivo de não ser reconhecido», e procurou torná-lo também um «instrumento capaz de revelar uma realidade oculta” (SARTORI \& LANATA, 1984, p. 9). Ele não estava sozinho nesse proceder. Juntamente com nomes como Adolphe Appia, Constantin Stanislavski, Vesevolod Meyerhold, Jacques Copeau encarou a questão da renovação do teatro por meio da formação do ator. Como eles, desejou que o ator se tornasse um criador, que ultrapassasse a submissão ao texto escrito, adquirisse o domínio técnico de todos os seus meios de expressão e chegasse a uma composição artística não-naturalista que reduzisse ao mínimo a casualidade e as incertezas da inspiração, como ocorre com "as expressões de uma máscara ou os movimentos da marionete” (MARINIS, 2000, p. 165). Seguindo esse ponto de vista, ao referir-se ao "velho teatro japonês", Charles Dullin confessa dever muito a este, por ter fortalecido as suas idéias sobre uma renovação do espetáculo teatral, e afirma que os atores japoneses, com sua perfeição técnica, “devem muito às marionetes e às máscaras” (1946, p. 59-60, 61), as quais, portanto, passam a ser modelos para um ator que deve ter controle sobre si mesmo (inclusive do seu rosto), visto que "tudo que é acidental é contrário à Arte” (CRAIG, s.d., p. 88).

O primeiro exercício com máscara realizado na Escola do VieuxColombier, ainda em organização (1920), foi registrado pelas notas de Suzane Bing. "Diante de cinco ou seis amigos da casa", numa terça-feira, 22 de junho, o

Março $2009-N^{0} 12$ 
grupo de alunos apresentou a Copeau uma charada. Para representar o adjetivo "sujo", o primeiro quadro se situava num banheiro, onde adolescentes assistidos pelo funcionário da escola faziam a higiene matinal. Um retardatário, ainda completamente adormecido, esfregava rapidamente a ponta dos dedos e do nariz. Usava uma máscara cinza; a dos colegas era branca (BING in COPEAU, 2000 , p. 225). Bing observa que as pernas e os pés dos alunos parecem não participar do jogo, o que reforça a idéia de trabalhar corporalmente com eles ( $i d$., $i b .$, p. 226). Segundo ela, Copeau percebe que "poderão ser feitas, principalmente com as crianças (...), coisas que nunca foram experimentadas em cena" (id., ib., p. 225). As suas notas de agosto de 1920 representam uma etapa fundamental na reflexão pedagógica de Copeau, que escreve em seu diário, em 13 de agosto de 1920: “(...) nada existirá enquanto não houver a Escola”. Por um lado, existe a idéia de um ensino articulado, compreendido não como ponto de encontro de várias técnicas, mas como o resultado de um método geral único. Por outro lado, ele se distancia dos "cabotinos do músculo" e da "afetação" que os novos métodos correm o risco de produzir. Em sua opinião, os problemas prioritários na formação do ator são: o conhecimento e a experiência do corpo humano e a busca de uma "sinceridade" compreendida como um estado de calma, de descontração, de silêncio, de imobilidade indispensável para chegar à expressão e para harmonizar ação externa e interna do ator, num agir/ reagir físico que não seja falseado por uma premeditação excessiva (COPEAU in JOMARON, 1992, p. 734-736). Assim, tratar-se-á, na Escola do Vieux Colombier $(1921$ - 1924) de ministrar cursos de cultura teatral, de cultura geral e, principalmente - na trilha de Craig, Stanislavski, Dalcroze — de disciplinas técnicas que visem a um treinamento corporal, gestual e vocal mais completo. Portanto, o ensino será baseado na educação corporal. O texto será um ponto de chegada, não de partida, o que não significa que sua importância fique diminuída. Na verdade, para que a palavra exista, na ação dramática, ou para que volte a ser "justa, sincera, eloquente e dramática", o ator deverá ser, "acima de tudo, um ser que age, uma personalidade em movimento" (COPEAU, 1974, p. 114). A máscara na Escola é, então, o principal meio técnico e expressivo para os exercícios e para as dramatizações. Trabalhar com ela compreende, assim, uma série de exercícios gradativos. Da imobilidade e do silêncio com as máscaras neutras, até à dramatização coral.

Os trabalhos práticos dos alunos, realizados a partir de dezembro de 192 1, com a orientação de Louis Jouvet, foram consignados por Marie-Hélène Dasté num caderno (como fabricar e utilizar colas e óleos, corantes químicos e vegetais para tecidos e diversos materiais...) A primeira parte do caderno trata de Modelagem, Moldagem, Execução das Máscaras. Sete matérias e procedimentos diferentes foram tentados por sete alunos ou equipes. A receita foi conservada, quer se tratasse de cola e papel deixado de molho, de tarlatana colada, de pequenas tiras de papel e tarlatana, de moletom branco 


\section{Urdimento}

embebido em goma laca quente (com farinha espessante), de camadas de pano unidas por cola de pasta e reforçadas com tarlatana, com pano, tarlatana e reforço de papel para a testa e a face, e até pasta feita de serragem de madeira, de caulim e de água resinosa, cozida no forno... Tais máscaras não são perfeitas: pequenas demais, estreitas, impedem o movimento e a articulação das palavras. Machucam os atores. Aquecem sobremaneira, porque os olhos e a boca ficam excessivamente colados ao rosto. Algumas têm um cheiro desagradável e rugosidades dentro delas.

Feitos em janeiro de 1922, os primeiros exercícios com máscara deram força e segurança aos participantes - "uma espécie de estabilidade e de consciência de todos os seus gestos e de si mesmo” (DASTÉ in COPEAU, 2000, p. 274).

Copeau não desejava criar atores isolados das realidades práticas da cena, dos bastidores e do ateliê, mas sim seres polivalentes capazes de trabalhar, em equipes, para a realização de todos os instrumentos de um espetáculo. Assim, toda a última parte do caderno contém receitas de pasta plástica; de pomada e de pó para a pintura de Pierrot [Pierrô]; procedimentos de pintura e corantes com anilina; pintura a óleo e pintura com cola, sem esquecer, em cada caso, a limpeza dos pincéis e dos recipientes (id..ib. p. 275). Em reação a um ensino preocupado com "modelar 'especialistas' (...) tendo em vista um diploma ou um contrato, como se a prática de uma 'especialidade' não pudesse se coadunar com uma cultura geral” (CHENNEVIERE in id., ib., p. 276), o ensino da Escola do Vieux-Colombier "ganha força na sua unidade. Não basta que o programa seja rico e diverso: é preciso, sobretudo, que seja coerente. Não basta que os professores sejam peritos em sua parte, é preciso que colaborem efetivamente uns com os outros. (...)" (in id., ib. p. 277).

Nas anotações relativas às atividades de 1921-1922, Marie-Hélène Dasté (in id., ib., p. 298-301) passa a limpo algumas aulas e projetos de exercício. Por meio dessas páginas, podemos inteirar-nos de princípios expostos por Copeau sobre o trabalho com a máscara:

- Todo movimento é determinado por uma finalidade $e$ tem a sua forma e o seu ritmo próprios. Para que um movimento seja legivel, precisa ser contínuo, ir até o fim e tender a uma finalidade;

- Ter o sentido dramático é poder apropriar-se de outrem: sair de si mesmo para apropriar-se de outrem, identificar-se a outrem. Não podemos doar-nos se não nos possuímos - (...) Para possuir a si mesmo, é preciso concentrar-se, recolher-se. É preciso um recolhimento anterior a qualquer ação. É nesse recolhimento prévio que se faz a préformação da ação. A pré-formação da ação é envolvida no silêncio do recolhimento — depois vem o suspense, o ataque, e por fim a ação. 
Urdimento

- Estado - necessidade de adorar - instinto dramático - celebração - rito - culto - ação=drama - finalidade movimento - ritmo e sentido dramático.

- O suspense é o ponto intermediário, quase imperceptivel, entre o recolhimento e o ataque. (...)

- O movimento não é o complemento do texto - a ação é a coisa principal e a palavra é, ao contrário, apenas o seu complemento.

- Todo movimento deve permanecer puro e simples, desenvolver-se até o fim, ser contínuo e ter um sentido.

- Estado prévio a qualquer ação:

recolher-se (silêncio, descontração)

recolhimento (pré-formação)

suspense

ataque.

- Toda expressão tem um movimento, seja exterior (centrifugo), seja interior (centrípeto).

- Para ser dramática, uma expressão precisa ser legível; para ser legivel, precisa ter um sentido e ser contínua.

- O corpo é o instrumento, o meio de expressão. Quando uma parte desse instrumento foi impressionada ou tocada, essa parte é a primeira que se estende, que se dirige para a coisa que a tocou ou impressionou, e leva consigo todo o corpo. A direção é dada pela parte do corpo mais sensivel à causa da ação.

- Se alguma coisa toca a vista, começa-se por virar os olhos para o ponto que os atrai, e depois a cabeça acompanha o movimento e puxa inclusive o corpo. A direção é dada pelos olhos.

- Ouvir: é o ouvido que se estica e dá a direção ao resto do corpo.

- Para pegar, é a mão que se estica primeiro e dirige o movimento que se desenvolve até ser ultrapassado o espaço necessário para pegar o objeto (...).

- Todo movimento deve ter uma progressão constante. Ele não pode chegar a um grau muito forte e depois recair, e depois subir novamente, sem perder a sua forma e tornar-se incompreensivel para o espectador.

Considerando que, "com a máscara, sentimos subitamente uma força e uma segurança totalmente desconhecidas" e que, "com o rosto encoberto, recobra-se confiança e ousa-se o que nunca se ousaria com o rosto descoberto", já que "a máscara impõe grande força e amplitude em cada movimento, exige movimentos completos e desenvolvidos até o fim, que tenham o mesmo caráter calmo, regrado e forte, o mesmo estilo que a própria máscara”, e que 


\section{Urdimento}

"expressamos com a máscara de um modo muito mais legível e impressionante sentimentos que se tem o hábito de expressar pelo jogo do rosto", são executados na Escola exercícios com máscaras (o texto não explicita de que tipo de máscaras se trata), para dar-se conta da importância das mãos quando o rosto é substituído pela máscara; para escolher o movimento ou a posição um(a) só - mais expressivos daquilo que deve ser expresso, e o levar ao seu mais alto grau de desenvolvimento; para perceber a direção e a continuidade da ação, e a relação de duração entre as várias fases da ação (in id., ib. p. 301-305). Vejamos dois exemplos de exercícios sobre a direção e a continuidade da ação:

\section{Exercícios feitos por Monique:}

$1 \%$ a parte atraída do seu corpo é o olho. Seu movimento tem por direção o assoalho.

a. o começo: ela põe a máscara.

b. ausência de ação ou outra ação prévia: ela caminha na sala de cabeça baixa.

c. percebe no chão um pedaço de linha ou um alfinete. Sua caminhada é suspensa gradualmente.

d. ela vê, olha com atenção.

e. a curiosidade desencadeia o movimento, que se desenvolve para baixo, guiado pelo olho, que olha para o chão - o corpo se dobra na direção do objeto. Quando se acocora no chão, sua mão estica com apenas dois dedos estendidos, porque o objeto é muito pequeno.

f. ela toca o objeto, pega-o - ela o examina, e depois o joga fora: fim da ação.

$2^{\circ} /$ a parte atraída do seu corpo é o ouvido. O seu movimento tem por direção o lugar de onde vem o som que ela percebeu.

a.o começo: ela põe a máscara.

b.ausência de ação ou outra ação prévia: sentada no canto da mesa, de viés, com as costas voltadas para a porta, de onde virá o som que vai impressionar o seu ouvido, ela está lendo um caderno.

c.percebe o som.

d.seus olhos abandonam o caderno - ela escuta - a atenção nasce; guiada pelo ouvido, a sua cabeça se desvia levemente - depois o corpo, seguindo o mesmo movimento, começa a virar, enquanto a mão que segura o caderno cai sobre os joelhos; um primeiro pé toca o chão, ela pousa o caderno, desce completamente da mesa, escuta de novo, imóvel (plataforma); sempre guiada pelo ouvido, começa a caminhar na direção do som que ela 


\section{Urdimento}

$$
\begin{aligned}
& \text { ouviu — o corpo está inclinado, guiado pelo ouvido - } \\
& \text { perto da porta ela escuta novamente. } \\
& \text { e.depois as mãos se aproximam da porta - ela abre, escuta, e a } \\
& \text { fecha outra vez: fim da ação.» (in id., ib., p. 303). }
\end{aligned}
$$

No decorrer do mesmo ano, foram praticados também exercícios de conjunto, com indicação de tempo.

Os exercícios individuais, improvisados, possuíam títulos: $O$ ser que vai comer geléias no armário, $O$ roubo, $O$ ser que se sentou num formigueiro, Um ser que saiu à noite no vento e na chuva, Dor de barriga, Batalhas, O despertar dos seres depois do inverno, O ser que está com frio e que desabrocha no sol. Este último foi improvisado diante dos espectadores no exame de fim de ano, em 1922:

Ela chega. Atitude ensimesmada, braços cruzados. Tirita de frio - Dá umas olhadas súplices para o sol — Olha ao seu redor Senta-se tiritando de frio; enfia a cabeça entre os joelhos - Faz uma bola com o corpo - Breve pausa - Depois começa o desabrochar do pequeno ser, causado pelo sol que sai das nuvens. A seguir vem o despertar, que continua, e acaba o desabrochar e o degelo do ser paralisado pelo frio. (in id., ib., p. 306-7).

Constam também da relação mais de um jogo com diabinhos, nos quais os atores-aprendizes contracenam com um fantoche, carinhosamente chamado por eles de Goldoni, em homenagem ao dramaturgo italiano. Esses jogos serviram para formar «um coro de demônios em surdina que dão uma idéia da perfeição» (DUBECH in id., ib., p. 312). Vê-se aqui a interligação da Escola com o Teatro do Vieux-Colombier, pois em 16 de junho de 1922 estreou, com a direção de Copeau, Saül [Saul], de André Gide. Na ocasião, um crítico assim se pronunciou:

O Sr. André Gide não tem bobos da corte, como Shakespeare. Ele os substitui por uma trupe de demônios que é pitoresca, inquietante, burlesca. O Sr. Copeau se empenhou em nos apresentar essa companhia de personagens irreais. São quase animais. Fazem pensar nos macacos que conversam com as feiticeiras de Geethe. Os papéis são confiados aos alunos do Vieux-Colombier. Eles evoluem com arte. Seus movimentos, suas atitudes são admiráveis. Suas máscaras são expressivas e tristes. (...)

Em Saül [Saul], os demônios rondam o trono, brincam com o cetro e com a coroa, esvaziam a taça régia. Um deles salta nos ombros do soberano errante. (...) As entradas dos demônios merecem toda a nossa admiração (...) (NOZIÈRE in id., ib., p. 311) 


\section{Urdimento}

${ }^{3}$ Esses exercícios serão reutilizados mais tarde na Borgonha, no trabalho dos Copiaus, e, em Paris, no dos Comédiens Routiers [Atores Itinerantes].

${ }^{4} 0$ projeto mais importante diz respeito a duas fábulas: La belle au bois dormant $[\mathrm{A}$ Bela Adormecida no Bosque ] e Le chant du jeudi $[0$ Canto da Quinta-feira]. Esse tipo de trabalho foi retomado por Chancerel com os Comédiens Routiers [Atores Itinerantes].

${ }^{5}$ Notas de Vitray para a abertura das aulas (programa de novembro de 1923): "(1) Utilização da máscara para aumentar a consciência das possibilidades do corpo; (2) pôrse em estado de disponibilidade; (3) continuidade, direção do movimento: a parte do corpo mais interessada guia o movimento; (4) desenvolvimento do sentido da duração e da estrutura de uma cena, por meio de improvisações de duas a quatro pessoas, estabelecendo claramente 0 início, 0 ponto culminante e a conclusão;
No exame de fim de ano, em 1922, foram apresentados nove exercícios de máscara. Um deles, intitulado As Feiticeiras, foi inventado e executado coletivamente, a partir de uma série de exercícios simples, individuais e coletivos (continuidade do movimento, atenção, escutar e perceber; sentar-se, levantar-se em diversos tempos, exercícios preparatórios à composição dos demônios de Saül [Saul] (DASTÉ in id., ib., p. 313, 315). Portanto, as máscaras expressivas, evitadas no início dos estudos, devido ao risco de influenciar o aluno e de falsear o seu modo de trabalhar, foram gradativamente utilizadas durante essa educação do movimento silencioso, quando o aprendiz já tivesse condições de assumi-las sem afetação, após ter-se familiarizado com a máscara nobre (neutra), e ter feito exercícios de mimo alegórico (O Cansaço, A Fome, O Medo, etc.), base das improvisações e das dramatizações dos anos seguintes ${ }^{3}$. Com improvisações de grupo, foram estudados também o movimento não humano e as personagens-tipo da Comédia Nova (um dos objetivos de fundo de toda a pesquisa de Copeau), integrando os estudos de pantomima com os exercícios fonéticos e verbais, e relacionando os exercícios com o estudo da cultura e do teatro gregos nos cursos abertos (direção de Louis Jouvet, Georges Chennevière e Copeau), o que convergiu para uma versão do mito de Psique, composta, recitada, dançada e cantada coletivamente. O estudo da máscara prosseguiu no segundo ano (1922 - 1923), juntamente com o do mimo, no curso de Educação Dramática (integrado com os outros, sobretudo com Teoria e Dicção). Prosseguiu também o trabalho de dramatização de fábulas, mitos e provérbios4. Foram incorporados então os conceitos de base da escola: o movimento estilizado (pantomima); as máscaras; a composição rítmica.

No terceiro ano $(1923-1924)$ os alunos foram estimulados a desenvolver as pesquisas sobre o mimo, a máscara, a voz, os grommelots [gromelôs, blablação] e as improvisações sobre personagens-tipo, por meio de novos exercícios mais complexos e roteiros mais longos ${ }^{5}$. Esse trabalho resultou em dois espetáculos de conclusão da experimentação pedagógica de Copeau no Vieux Colombier: $\operatorname{Kantan}^{6}$ e uma antologia de trechos variados como apresentação de fim de ano.

O trabalho de ator realizado por Jacques Copeau não visava, portanto, a tornar o ator um virtuose do músculo, um atleta ou um saltimbanco, mas um ser humano consciente de suas possibilidades expressivas. Adquirida a expressividade física, tratava-se de pôr o corpo do ator a serviço do poeta dramático e do encenador.

A expressão do corpo em silêncio, a improvisação silenciosa e o uso da máscara, na Escola do Vieux Colombier, desempenhavam uma função instrumental. Não constituíam um fim em si mesmas. O caminho ia da privação inicial do texto à sua redescoberta, no final dos estudos. A apresentação de fim de ano dos alunos iniciava sempre por exercícios puramente físicos, e acabava pelas dramatizações coletivas faladas, depois de haverem sido 


\section{Urdimento}

propostos vários exemplos de improvisações mímicas e sonoras, individuais e coletivas. Nessa trilha, os espetáculos dos Copiaus e dos Comédiens Routiers [Atores da Estrada], os primeiros passos do mimo corporal de Decroux e dos mimodramas de Barrault dão grande importância às cenas mimadas. Pouco a pouco, pelo que Barba chama “a deriva dos exercícios”, o que era um meio se torna um fim em si.

Ao fechar a Escola e o Teatro do Vieux-Colombier, em Paris, em 1924, Jacques Copeau instalou-se na Borgonha, primeiramente em Morteuil, depois em Pernand-Vergelesses, com trinta e cinco pessoas, para constituir uma espécie de laboratório de pesquisas e produções teatrais. A aventura teve duração efêmera (de outubro de 1924 a fevereiro de 1925), devido a problemas financeiros. Os remanescentes em Pernand fundaram a companhia intitulada Les Copiaus. O seu Journal de bord [Diário de Bordo] (GONTARD org., 1974) registrou os fatos significativos da trupe (1924-1929): pesquisa de personagens, improvisações, trabalho corporal e vocal, confecção e utilização de máscaras, cujo ensino foi atribuído a Marie-Hélène Dasté. Ao abandonar Paris e o seu teatro/escola, Copeau queria dedicar-se à preparação de uma «Comédia Nova», com a busca de tipos fixos atuais (o burguês, o nobre, o vendedor de vinho substituiriam Arlequim, Pierrô, Colombina). Gerações sucessivas adotaram, direta ou indiretamente, a prática e os ensinamentos de Copeau (Charles Dullin, Louis Jouvet, Léon Chancerel, Étienne Decroux, Jean Dasté, Jacques Lecoq, Ariane Mnouchkine), na França e através do mundo. Suas considerações sobre a máscara continuam a fornecer elementos de reflexão:

$O$ ator que atua com máscara recebe desse objeto de papelão a realidade da sua personagem. É comandado por ela e a ela obedece irresistivelmente. Assim que a põe, sente surgir nele uma existência de que (...) nem sequer suspeitava. Não é somente o seu rosto que se modifica, mas toda a sua pessoa, o próprio caráter dos seus reflexos, em que já se pré-formam sentimentos que ele era igualmente incapaz de experimentar e de fingir com o rosto descoberto (COPEAU, 1929, p. 14-15).

\section{Referências bibliográficas}

BING, Suzanne. «Le [mardi] 22 juin [1920]» [22 de junho [1920], terça-feira], in COPEAU, Jacques. Registres VI. L'Ecole du Vieux-Colombier. Textes établis, présentes et annotés par [Registros VI. A Escola do Velho Pombal. Textos estabelecidos, apresentados e anotados por] Claude Sicard. Paris: Gallimard, 2000.

CHANCEREL, Léon. LE MASQUE (premier cahier) [A Máscara (primeiro caderno]. Prospero [Próspero] n ${ }^{\circ}$ 10. Por Léon Chancerel com a colaboração de Robert Barthès. Paris: L. H. L., s.d.

Março 2009 - № 12

Copeau e a máscara. José Ronaldo Faleiro
(5) 0 estudo das relações entre as partes de uma ação e de uma improvisação idéia da construção dramática; (6) mimo e trabalho coral para desenvolver a sensibilidade em relação ao espaço dos outros atores e a adesão à estrutura de base por meio de jogos, charadas e histórias, como pura improvisação". — V. Marco DE MARINIS (1993, p. 87).

${ }^{6} \mathrm{~A}$ apresentação de um Nô é justificada pela oportunidade que ele dá a Suzana Bing de reunir os estudos musicais, dramáticos e

plásticos que haviam sido trabalhados durante três anos. Além disso, trata-se de interessar-se pela forma dramática mais rigorosa, a que requer do intérprete uma excepcional formação técnica. 0 teatro japonês aparece como desafio e como formidável meio de verificação de três anos de intenso trabalho pedagógico. 


\section{Urdimento}

COPEAU, Jacques. «Paradoxe sur le Comédien présenté par Jacques Copeau» [Paradoxo sobre o Ator, apresentado por Jacques Copeau], in DIDEROT, Denis. Paradoxe sur le Comédien [Paradoxo sobre o Ator]. Paris: Plon, 1929.

COPEAU, Jacques. «Place aux jeunes» [Deixem Passar os Jovens] (1937), in Registres I: Appels [Registros I: Apelos]. Paris: Gallimard, 1974.

COPEAU, Jacques, in JOMARON, Jacqueline de. «Jacques Copeau: le tréteau nu» [Jacques Copeau: o tablado nu], p. 731-741. JOMARON, Jacqueline de (org.) Le Théâtre en France du Moyen Âge à nos jours [O Teatro na França da Idade Média aos nossos dias]. Prefácio de Ariane Mnouchkine. Paris: Armand Colin, 1992.

COPEAU, Jacques. Registres VI. L'Ecole du Vieux-Colombier [Registros VI. A Escola do Velho Pombal. Textes établis, présentes et annotés par [Textos estabelecidos, apresentados e anotados por] Claude Sicard. Paris: Gallimard, 2000.

CRAIG, Edward Gordon Craig. Da Arte do Teatro. Tradução, prefácio e notas de Redondo Júnior. Lisboa: Arcádia, s.d.

DASTÉ, in COPEAU, Jacques. Registres VI. L'Ecole du Vieux-Colombier ¿Registros VI. A Escola do Velho Pombal. Textes établis, présentes et annotés par [Textos estabelecidos, apresentados e anotados por] Claude Sicard. Paris: Gallimard, 2000.

DULLIN, Charles. Souvenirs et notes de travail d'un acteur [Lembranças e Notas de Trabalho de um Ator]. Paris: Odette Lieutier, 1946.

FO, Dario. Manual Mínimo do Ator. Franca Rame (org.). Tradução de Lucas Baldovino e Carlos David Szlak. São Paulo: SENAC São Paulo, 1998.

GONTARD, Denis (org.). Journal de bord des Copiaus [Diário de Bordo dos Copiaus]. Paris: Seghers, 1974.

HUSSENOT, Olivier. «L'Art du masque. Pour et contre le masque» [A Arte da Máscara. A favor dela e contra ela], in Bulletin des Comédiens Routiers d'Ile-deFrance [Boletim dos Atores Itinerantes de Ilha-da-França ], nº 1, nov. 1932.

MARINIS, Marco De. Mimo e teatro nel Novecento [Mimo e teatro no século XX]. Firenze: La Casa Usher, 1993.

MARINIS, Marco De. In cerca dell'attore. Un bilancio del Novecento teatrale $[\mathrm{Em}$ busca do Ator. Um balanço do Teatro no Século XX].Roma: Bulzoni, 2000.

SARTORI, Donato \& LANATA, Bruno, con la collaborazione di [com a colaboração de] PIIZZI, Paola. Maschera e Maschere. Storia, morfologia, técnica [Máscara e máscaras. História, Morfologia, Técnica. Firenze: Centro Maschere e Strutture Gestuali/La Casa Usher, 1984.

STREHLER, Giorgio. Per un teatro umano [Para um Teatro Humano]. Sinah Kessler (org.) Milano: Feltrinelli, 1974. 